\title{
Correspondence
}

\section{Pulmonary damage with gold or penicillamine}

SIR, We were interested to read the report of Scott et al. ${ }^{1}$ but consider that they have confused 2 clinical entities and that their conclusions are misleading.

We agree that gold causes an acute pulmonary syndrome as they have described. Our own review article $^{2}$ has summarised the usual features-the onset of dyspnoea and cough, sometimes with fever, the finding of fine basal rales clinically, a restrictive ventilatory defect, and the radiological evidence of pulmonary infiltrates, which all occur after a total gold dose of between 175 and $840 \mathrm{mg}$ in the reported cases. We have termed this syndrome 'gold lung.'

However, of the 7 patients treated with D-penicillamine reviewed by Scott et al. only 3 had an undoubted acute syndrome akin to gold lung, which might be called 'penicillamine lung.' The other 4 patients developed a form of Goodpasture's syndrome. Radiological 'infiltrates' seen in this condition are due to haemorrhage, and any fibrosis that may be seen is secondary to haemosiderin deposition. We cannot accept that Goodpasture's syndrome is a form of pulmonary interstitial fibrosis or of 'diffuse interstitial lung disease,' a rather loose term used by Scott et al. following the criteria of Walker and Wright. ${ }^{3}$ We would further point out that in the quoted paper by Sternleib 4 all 3 patients had Wilson's disease and were given much larger doses of D-penicillamine than are used in rheumatoid arthritis, and that the lung histology reported (and this only in one patient) does not support a diagnosis of 'diffuse interstitial lung disease.'

Our own review article shows that in cases of 'gold lung' recovery is the rule. ${ }^{2}$ Goodpasture's syndrome was untreatable, and nearly always fatal, at the time of Sternleib's paper, but the prognosis is now much better following the introduction of plasmapheresis. Thus it is most important from the point of view of management to make a clear distinction between the syndrome of 'penicillamine lung' and penicillamine-induced Goodpasture's syndrome.

The contention that 'diffuse interstitial lung disease is a serious adverse reaction to gold and penicillamine' is unsupportable. Of the 4 deaths described in Scott et al.'s report 3 were of patients with Goodpasture's syndrome, which is unsurprising. The fourth death was of a patient in Gould's series ${ }^{5}$ with gold lung, but this was not the causefof death-the patient died of a myocardial infarction 24 hours after admission. The figures now look rather different. Twenty-three cases of gold or penicillamine lung are reported; 10 resolved completely, 10 improved, and one died for another reason. Of the 2 who failed to improve, one had pre-existing pulmonary fibrosis and one was treated with penicillamine for a further 5 months after the onset of symptoms. Earlier recognition of 'penicillamine lung' might have produced a different outcome in this last case.

Goodpasture's syndrome is a recognised complication of penicillamine treatment and is listed in the Distamine data sheet. Gold and penicillamine lung are unpleasant early complications of treatment but are reversible. They are not common: in our own study group 71 patients have had gold and none have developed the acute syndrome.

\section{ANDREW BAMJI \\ NIGEL COOKE \\ The Middlesex Hospital, London WIP 9PG}

\section{References}

1 Scott D L, Bradby G V H, Aitman T J, Zaphiropoulos G C, Hawkins C F. Relationship of gold and penicillamine therapy to diffuse interstitial lung disease. Ann Rheum Dis 1981; 40: 136-41.

${ }^{2}$ Cooke N T, Bamji A N. Gold lung. Rheumatol Rehabil in press.

3 Walker W C, Wright V. Pulmonary lesions and rheumatoid arthritis. Medicine 1968; 47: 501-20.

4 Sternleib I, Bennett B, Scheinberg I H. D-penicillamine induced Goodpasture's syndrome in Wilson's disease. Ann Intern Med 1975; 82: 673-6.

5 Gould P W, McCormack P L, Palmer D G. Pulmonary damage associated with sodium aurothiomalate therapy. $J$ Rheumatol 1977; 4: 252-60.

SIR, Drs. Bamji and Cooke raise several points and refer to their review article, though this was in press when they wrote and its contents unknown to us. They imply that pulmonary complications of gold and penicillamine are not serious adverse reactions. We cannot agree with this merely because they are not necessarily fatal. One patient (case 1 in our series) was cyanosed, desperately ill, and needing continuous oxygen.

Nosological debates are characterised by 'splitting' or 'lumping', especially when the evidence is incomplete. Although we think that the patients we studied and reviewed with lung disease associated with penicillamine should be considered as a single group, we did indicate which ones were originally described as having Goodpasture's syndrome. However, the problem is complicated, since the evidence that any of these patients had this syndrome is incomplete.

Finally, about terminology - the term 'gold lung' was first used by James, Whimster, and Hamilton ${ }^{1}$ and of course is not an original term coined by Bamji and Cooke. Its advantage as a descriptive term is minimal. After all, one does not refer to 'gold skin' or 'penicillamine ageusia.'

DAVID L SCOTT CLIFFORD HAWKINS Queen Elizabeth Hospital, Birmingham B15 2TH

Reference

1 James D W, Whimster W F, Hamilton E B D. Gold lung. Br Med J 1978; ii: 1523-4. 